\title{
Endoscopic Management of Benign Colonic Obstruction and Pseudo-Obstruction
}

\author{
Su Jin Jeong and Jongha Park \\ Division of Gastroenterology, Department of Internal Medicine, Haeundae Paik Hospital, Inje University College of Medicine, Busan, Korea
}

There are a variety of causes of intestinal obstruction, with the most common cause being malignant diseases; however, volvulus, inflammatory bowel disease or diverticulitis, radiation injury, ischemia, and pseudo-obstruction can also cause colonic obstruction. These are benign conditions; however, delayed diagnosis of acute intestinal obstruction owing to these causes can cause critical complications, such as perforation. Therefore, high levels of clinical suspicion and appropriate treatment are crucial. There are variable treatment options for colonic obstruction, and endoscopic treatment is known to be a less invasive and an effective option for such. In this article, the authors review the causes of benign colonic obstruction and pseudo-obstruction and the role of endoscopy in treating them. Clin Endosc 2020;53:18-28

Key Words: Balloon dilatation; Enteral stent; Intestinal obstruction

\section{INTRODUCTION}

Intestinal obstruction is the partial or complete blockage of intestinal contents, and it is divided into mechanical or functional obstruction, called pseudo-obstruction. ${ }^{1}$ Both acute colonic obstruction and pseudo-obstruction have numerous causes, including malignant and benign diseases. The clinical presentations of colonic obstruction are typically periumbilical or hypogastric pain varying from mild to severe intensity and associated with abdominal distention. The symptoms appear after a few days of obstruction, and the initial symptoms, such as abdominal fullness and discomfort, are relatively nonspecific; therefore, careful attention should be paid to early diagnosis. Acute colonic obstruction most commonly occurs as a result of malignant diseases; however, benign diseases

Received: February 24, 2019 Revised: July 24, 2019

Accepted: August 5, 2019

Correspondence: Jongha Park

Division of Gastroenterology, Department of Internal Medicine, Haeundae Paik Hospital, 875 Haeun-daero, Haeundae-gu, Busan 48108, Korea

Tel: +82-51-797-0200, Fax: +82-51-797-1341, E-mail: neakker@gmail.com

ORCID: https://orcid.org/0000-0002-5241-1747

cc This is an Open Access article distributed under the terms of the Creative Commons Attribution Non-Commercial License (http://creativecommons.org/ licenses/by-nc/3.0) which permits unrestricted non-commercial use, distribution, and reproduction in any medium, provided the original work is properly cited. can also cause this obstruction. ${ }^{2}$ Fifteen to twenty percent of patients with colorectal cancer develop bowel obstruction. ${ }^{1,3-6}$ Approximately $60 \%$ of significant colonic obstructions are due to primary colonic malignancies, and of these, the majority are localized to the left side of the colon, with the sigmoid colon as the single most common location. ${ }^{7}$ In addition to direct strictures caused by primary colorectal cancer, obstruction caused by metastatic colon cancer and external compression of other cancer in the pelvic cavity can also be classified as malignant strictures. Benign colonic obstruction may occur owing to various causes, such as postoperative anastomotic stricture, radiation injury, diverticulitis, ischemia, inflammatory disease (e.g., Crohn's disease), presence of foreign bodies, and intussusceptions. Meanwhile, pseudo-obstruction of the colon refers to a clinical group that shows radiological signs and symptoms of intestinal obstruction due to loss of intestinal motility without mechanical occlusion. ${ }^{8}$

Different methods have been used to treat colonic obstruction. For instance, patients with complete obstruction or gangrenous bowel should be referred for surgical consultation; conversely, those with strictures caused by benign diseases are widely treated with balloon dilatation and intralesional steroid injection, bougie dilatation, self-expandable metal stent (SEMS) implantation, and direct digital dilatation. In cases 
of malignant colonic obstruction, most of the diseases that cause it are persistent and progressive; thus, surgical methods and stent implantation are more commonly used, and balloon dilatation has also been attempted with limited success. In the present article, the authors discuss the indications, effectiveness, and methods of endoscopic treatment for benign colonic obstruction and pseudo-obstruction.

\section{BENIGN COLONIC OBSTRUCTION}

Benign colonic obstruction may occur owing to various causes (Table 1$)^{9}$ and acute obstruction owing to colonic volvulus, diverticulitis, intussusception, and hernia. Meanwhile, subacute benign colonic obstruction results from strictures (anastomotic strictures, inflammatory bowel disease [IBD; usually Crohn's disease], intestinal tuberculosis, or cytomegalovirus colitis) or extrinsic compression of the bowel. Surgical anastomotic site strictures have been reported to occur in up

Table 1. Differential Diagnosis of Colonic Obstruction ${ }^{9}$

\begin{tabular}{lcl}
\hline Intraluminal & Intramural & \multicolumn{1}{c}{ Extraluminal } \\
\hline Intussusception & Congenital & Mass compression \\
Impacted matter & Stenosis & Abscess \\
Feces & Atresia & Pregnancy \\
Foreign bodies & Imperforate anus & Neoplasia \\
Medications & Inflammatory & Cysts \\
Bezoars & Diverticulitis & Urinary retention \\
Meconium & Ulcerative colitis & Vascular malformation \\
Gallstones & Crohn's disease & Adhesions \\
Worms & Neoplasia & Hernias \\
Enteroliths & Benign & Volvulus \\
& Malignant & Pancreatitis \\
& Trauma/Iatrogenic & Endometriosis \\
& Hematoma & \\
& Stricture & \\
& Radiation & \\
\hline
\end{tabular}

to $30 \%$ of patients undergoing colonic surgery, and one study showed that strictures occurred in approximately $5 \%$ of patients admitted with IBD. ${ }^{10}$

\section{Colonic volvulus}

Colonic volvulus occurs when the bowel twists upon itself, resulting in obstruction; the most common locations are the sigmoid colon and cecum. ${ }^{11}$ In Korea, sigmoid volvulus accounts for $2 \%-3 \%$ of all intestinal obstructions. ${ }^{12}$ The most common clinical symptoms are sudden abdominal pain, abdominal distension, severe constipation, nausea, and vomiting. For sigmoid volvulus, the pathognomonic sign is a smooth and dilated balloon-like inverted $U$ or coffee-bean shape and loss of haustra, arising from the pelvis in a vertical or oblique direction. ${ }^{13}$ On axial computed tomography (CT) scans, a whirl sign may be apparent.

Torsion of the cecum is generally treated with surgery. However, in sigmoid volvulus, colonoscopy has the advantage of attempting endoscopic reduction as well as diagnosis. ${ }^{14} \mathrm{~A}$ typical endoscopic finding is the onset of torsion of the rotator cuff sphincter within $25 \mathrm{~cm}$ of the anal verge, and the enlarged bowel lumen can be observed when the air is injected and carefully passed through the torsion site. After the scope passes through the torsion site, suctioning the air straightens the tortuous colon, and the torsion is often resolved. When colonic volvulus is successfully endoscopically reduced, gas and feces are rapidly released from the dilated colon, which is filled with exudate, air, and stool. ${ }^{15}$ It is not always necessary to rotate the endoscope to straighten a twist; it can also be restored with minimal air suction and manipulation. The success rate of endoscopic reduction of sigmoid volvulus is approximately $85 \%{ }^{15}$ Because relapse after non-operative (endoscopic) decompression is common, elective surgery is generally recommended after endoscopic detorsion of the intestine. ${ }^{11}$ Emergency surgery should be considered if perforation, bowel infarction, peritonitis (e.g., mucosal ulceration, necrosis, or hemolytic secretion), or failed endoscopic decompression occur. Endoscopic decompression of cecal volvulus has been reported to be less effective than that of sigmoid volvulus. Nevertheless, successful endoscopic decompression

Table 2. Comparison of Clinical Guidelines ${ }^{17}$

\begin{tabular}{|c|c|c|c|c|c|c|}
\hline & BTS & Proximal colonic lesions & Palliative & Extra colonic obstruction & Benign lesions & Covered vs. Uncovered \\
\hline ESGE & $\triangle^{\mathrm{a})}$ & $\triangle$ & $\bigcirc^{b)}$ & $\triangle$ & $\mathrm{X}^{\mathrm{c})}$ & $={ }^{\mathrm{d})}$ \\
\hline ASGE & 0 & $\triangle$ & 0 & $\triangle$ & $\triangle$ & $<^{\mathrm{e})}$ \\
\hline KSGE & $\triangle$ & $\triangle$ & 0 & $\triangle$ & $\triangle$ & $=$ \\
\hline
\end{tabular}

ASGE, American Society of Gastrointestinal Endoscopy; BTS, bridge to surgery; ESGE, European Society of Gastrointestinal Endoscopy; KSGE, Korean Society of Gastrointestinal Endoscopy.

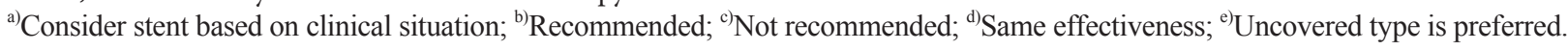


of cecal volvulus has been reported; however, the failure rate is high. Therefore, colonoscopy in cecal volvulus is not generally recommended; instead, surgical treatment should be recommended. ${ }^{16}$

\section{Endoscopic stent insertion for benign colonic ob- struction}

Endoscopic treatment for benign colonic obstruction can be performed with digital dilatation using balloons or rigid expanders, expanding with steroid injections or electroincision, or placing decompression tubes or expandable stents. ${ }^{9}$

The role of enteral stents for benign colonic obstruction is unclear. Although there is a slight difference in the summary of the clinical guidelines of the various institutes presented in a recent review, stent implantation in benign colonic obstruction is considered (Table 2). ${ }^{17}$ Commonly, a colonic stent is inserted aimed at malignant bowel obstruction; however, it can also be attempted to alleviate symptoms of obstruction due to benign conditions, such as postoperative stricture, stricture due to IBD, especially Crohn's disease, or stricture after radiation treatment. Although only a few cases have been reported, the success rate of colonic stenting for benign obstruction is lower $(36 \%-81 \%)$ than that for malignant obstruction, and the former has a higher recurrence rate, i.e., over $53 \% .{ }^{18}$ Further, complications associated with the procedure are reported to occur at $5 \%-50 \%$, which is higher than that in malignant obstruction. ${ }^{18}$

CT scan should be performed to confirm the lesion location and the length and occlusion of the closure site before the procedure. In cases of complete bowel obstruction, bowel cleansing with an oral preparation solution is unnecessary and is in fact avoided because it can worsen proximal dilatation. ${ }^{19}$ Antibiotic prophylaxis in colonic stenting is also generally not recommended. In a recent prospective study, 6.3\% (4/64)

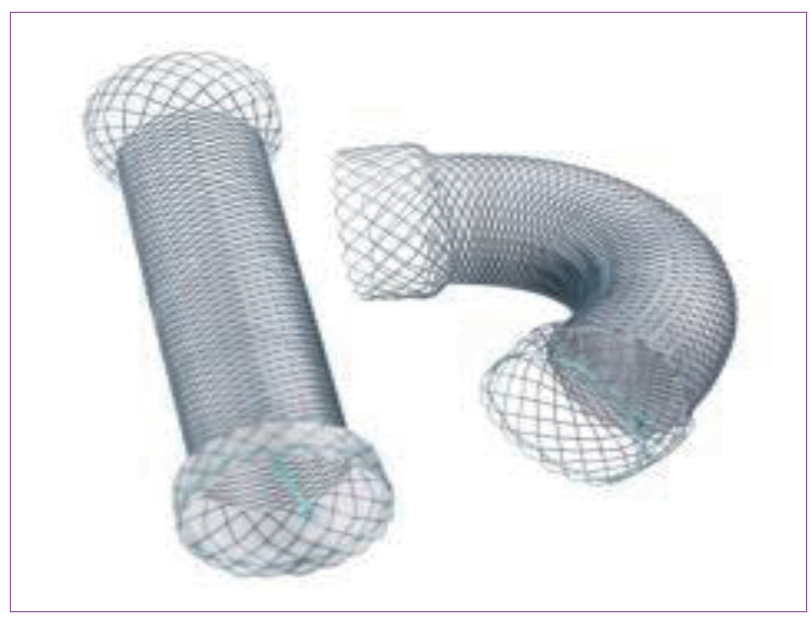

Fig. 1. Covered stent. of patients with positive blood culture findings for bacteria showed no clinically significant symptoms after stent placement. $^{20}$

Currently, most stents for the colon are SEMSs that form a mesh of metal and are either covered (the metal mesh is covered with a membrane material, such as polyurethane; Fig. 1) or uncovered (Fig. 2). Recently, various types of stents have been developed, such as a drug-eluting stent that inhibits the proliferation of benign tumors by covering an anticancer drug or a metal film that is attached to the outside of the membrane stent (Fig. 3) to reduce migration.

\section{Indication}

In the stent placement for benign colonic obstruction, there is still an uncertainty regarding indications and the timing of positioning and removal, and long-term results are lacking. ${ }^{18}$ Some experts recommend removing the SEMSs within 4-8 weeks after insertion before the stents are fully contained within the tissue. ${ }^{21}$

The only absolute contraindication of SEMS insertion is colonic perforation; diverticulitis with stricture is a known contraindication of SEMSs because of the high risk of perforation. ${ }^{22}$ SEMS insertion is also not recommended for obstruc-

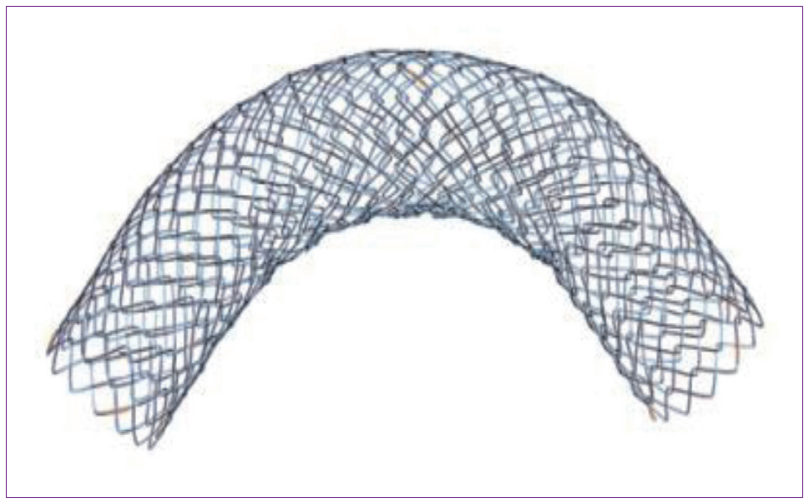

Fig. 2. Uncovered stent.

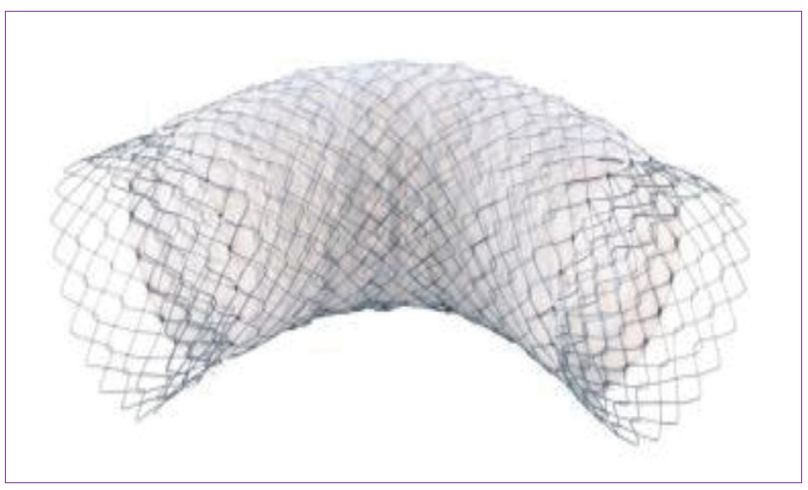

Fig. 3. Triple-layered stent. 
tions in the distal rectum, especially within $5 \mathrm{~cm}$ of the anal verge, as the stents may be irritating to the mucosa of the rectum and anus, resulting in severe pain or tenesmus and fecal incontinence. ${ }^{19}$ Prophylactic SEMS insertion for patients with no evidence of symptomatic obstruction is not recommended because the SEMS-related complication risks outweigh the potential benefits. ${ }^{23}$

\section{Insertion technique}

Colonic SEMS insertion techniques are divided into endoscopic or radiological placement. The stents are inserted using either a through-the-scope (TTS) technique or an over-theguidewire technique (non-TTS) via fluoroscopy. In the TTS technique, the guidewire, catheter, and SEMS are inserted through the working channel of the endoscope; currently, most colonic SEMSs are inserted using this technique. In this technique, the distal part of the lesion is first confirmed, and the guidewire is inserted sufficiently past the obstruction site, $20 \mathrm{~cm}$; thereafter, the catheter is inserted along the guidewire, and a radiocontrast dye is injected to confirm the morphology and the length of the obstructive lesion. The SEMS is then inserted along the guidewire. The length of the stent is recommended to be approximately $4-6 \mathrm{~cm}$ longer than that of the obstructive lesion, considering the shortening of the stent after insertion, so that each side of the stent will be $2-3 \mathrm{~cm}$ longer from the edge of the obstructive lesion. ${ }^{24,25}$ For effective decompression, the diameter of the SEMS should be at least $24 \mathrm{~mm}^{24,25}$ After the guidewire is positioned, the SEMS is guided through the proximal portion of the obstructive lesion along the guidewire and gradually spread so that its end is extended 2-3 cm from the proximal portion of the lesion; if appropriate extension is confirmed, the stent should be expanded while the endoscopic image is observed.

It should be noted that the rate of expansion should not be too rapid, and the "marker" of the stent should be kept $2-3 \mathrm{~cm}$ away from the distal part of the occlusion so that it can be fully opened, and the end of the stent can be deployed well. The ideal stent insertion timing is when the middle portion of the stent and that of the obstructive lesion align, and $2-3 \mathrm{~cm}$ of both ends is opened with an appropriate length of the stent. When the expansion of the SEMS is completed, the radiocontrast dye (e.g., Omnipaque ${ }^{\mathrm{TM}}$, iohexol; GE Healthcare, Shanghai, China) is administered to confirm the exact position and expansion of the inserted SEMS fluoroscopically; if the stent's length or technique is not appropriate, endoscopists can attempt to adjust the position using forceps or a similar device. When a SEMS is inserted through TTS placement, it is advantageous to use a dual-channel scope if possible because it is usually performed in a state in which the colon is not well cleaned, so suction and cleaning can be performed with a biopsy channel other than the working channel; this is then more advantageous in securing visibility.

Immediately after the successful insertion of a colonic stent, gas and feces in the large intestine are generally emitted, indicating success. After the procedure, a simple abdominal X-ray should be performed daily for 2-3 days to ensure the succession and check whether stent migration or any perforation has occurred. Over-the-guidewire placement is performed without endoscopic monitoring under fluoroscopic guidance. Retrospective comparison studies have revealed higher technical success rates when the combined TTS technique is used than when non-TTS placement is employed. ${ }^{23}$

\section{Outcomes of SEMS placement}

Colonic SEMS placement for benign lesions is still controversial. However, based on the current data, SEMS placement is a good option for avoiding emergency surgery and managing benign obstructive lesions in patients at a risk of undergoing surgery. Most studies on colonic SEMS placement for benign lesions are case reports or case series. In the largest series, 23 patients with benign obstructive disease were managed with SEMS placement. The clinical success rate was 95\% (22/23); however, the major complication rate was $38 \%$. The complications included migration, re-obstruction, and perforation. Additionally, only $42 \%$ of patients did not need a stoma created at the time of surgery. ${ }^{26}$ In one retrospective study, investigators evaluated 21 patients who had an SEMS placed for benign obstruction, such as anastomotic strictures, diverticular obstructions, or stricture, after radiation therapy. In this study, the clinical success rate was $76 \%$, and the complication rate was $43 \%$ (including six perforations); the majority of the complications occurred in patients with diverticular strictures. ${ }^{27}$ A systematic review of 21 published papers involving 122 patients with self-expanding stents for benign colorectal obstruction was published by Currie et al. ${ }^{22}$ in 2014. In their study, diverticulitis was the most common etiology (66/122, 54\%); the technical success rate was 94\% (115/122), and the clinical success rate was $87 \%(108 / 120)$. The overall perforation rate was $12 \%(15 / 122)$, and the overall re-obstruction rate was $14 \%$ (17/122). A stoma was avoided in $48 \%$ (23/48) of the bridge-to-surgery patients. ${ }^{22}$ In this systematic review, the authors did not recommend stenting in benign colonic obstruction because of the high incidence of associated complications.

\section{Complications}

Colonic stenting is known to be safe, with mortality of approximately $1 \%-2.7 \%$ in association with the procedure. ${ }^{28,29}$ The major complications include bowel perforation, pain, migration, and re-obstruction after decompression. In some 
meta-analyses, the incidence of perforation associated with colonic stenting is known to be approximately $4.8 \%$; in particular, a study reported that the incidence increases ( $10 \%$ vs. $2 \%$ ) during balloon expansion because of insufficient dilatation after stenting. ${ }^{30}$ Therefore, after self-expanding stent insertion, it is recommended to follow the expansion pattern for at least 2 days rather than proceeding with additional balloon dilatation. The incidence of stent migration to the distal or proximal part of the stricture lesion is reported to be $4 \%-10 \% .{ }^{28,30}$ Most of the migration occurs within 24 hours after insertion; however, some may occur within 1 week.

\section{Self-expandable plastic stents}

Self-expandable plastic stents (SEPSs) may also be used for definitive treatment of benign colonic obstruction. In a small case series of three patients, the authors reported successful resolution of benign postoperative strictures using covered esophageal SEPSs; however, spontaneous migration occurred in two patients. ${ }^{31}$ There are minimal data to recommend the use of SEPSs for benign colonic obstruction.

\section{New types of stents}

(1) Biodegradable stents

Recently, advances in material science have led to developments of new materials for biodegradable stents, and in some clinical studies, researchers have evaluated their usefulness (Fig. 4) in refractory benign esophageal strictures, including stenosis resulting from the use of corrosive agents or postoperative stenosis. ${ }^{32-36}$ However, information regarding the usefulness of biodegradable stents in the lower gastrointestinal tract is limited, although there are some case reports and small case series on biodegradable colonic stenting for benign lesions of the lower gastrointestinal tract. ${ }^{37-43}$ In one case report, a biodegradable stent made of polydioxanone was applied to a colonic stricture of Crohn's disease, and obstructive symptoms did not recur during the follow-up period of 16 months. ${ }^{42} \mathrm{~A}$ retrospective analysis of the early and late outcomes of biodegradable stent placement in managing refractory anastomotic colorectal strictures was published in $2013 .{ }^{44}$ In that study, 11 patients with benign postsurgical strictures located within

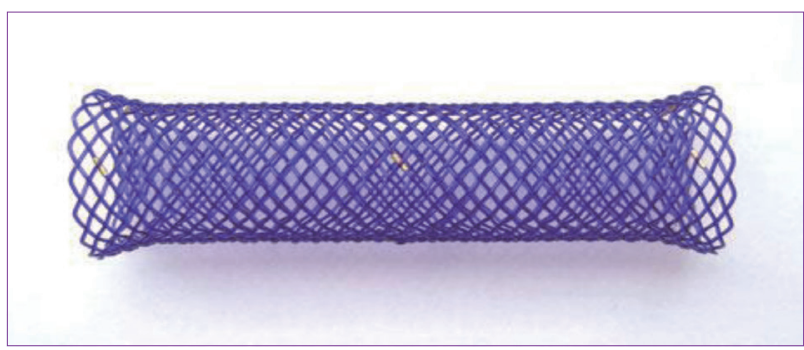

Fig. 4. Biodegradable esophageal stent.
$20 \mathrm{~cm}$ from the anal verge who underwent refractory to mechanical and pneumatic dilatation (at least three sessions) were investigated. The technical success rate was 100\% initially; however, stent migration was observed in four patients within the first 2 weeks after stent placement. Only five patients had complete resolution of the stricture; thus, the overall success rate was $45 \%$. However, in this study, biodegradable esophageal stents were used. Unfortunately, biodegradable stents with a larger caliber specially designed for colonic strictures are not yet available. The authors of the previously mentioned study thought that this might be related to the low clinical success rate owing to stent migration. Future developments of biodegradable stents for colonic strictures to overcome the existing limitations and larger prospective studies are needed.

\section{(2) Drug-eluting stents}

Drug-eluting stents are actively used in coronary artery occlusive disease but might also be useful in the gastrointestinal tract for reducing stent ingrowth or overgrowth. Although some animal studies have been conducted, most reports are for biliary stenosis; animal studies have been reported for treating obstruction due to colorectal cancer. ${ }^{45-51}$ Currently, there are no commercially available drug-eluting stents. Future development of these stents is expected to solve both invasions of tumor tissues in uncovered stents and stent migration of covered stents. Studies on the usefulness of drug-eluting stents in benign colon strictures are also needed.

\section{Endoscopic balloon dilatation for benign colonic strictures}

Endoscopic dilatation of colonic strictures is mainly used for benign indications, such as anastomotic strictures, strictures from IBD (usually Crohn's disease), colopathy induced by nonsteroidal anti-inflammatory drugs, and, rarely, diverticular strictures that develop following acute diverticulitis.

Endoscopic balloon dilatation is relatively simple and easy to perform, and the associated radial force is safer than the axial force in bougie dilatation; moreover, balloon dilatation is known to be more effective. ${ }^{52}$ Additionally, it can be used throughout the entire colon, while bougie dilatation is limited to the procedural area; bougie dilatation has been used to dilate post-transanal surgery strictures and those due to perianal Crohn's disease. ${ }^{53}$ Currently, dilatation of benign colonic strictures is typically performed using TTS balloons.

\section{Postoperative anastomotic strictures}

Postoperative strictures at the anastomotic site are more common in stapling devices than in manual anastomosis and are reported to occur in approximately $3 \%-30 \%$ of patients who underwent colonic resection. ${ }^{54,55}$ Although the exact 
mechanism of postoperative stenosis is not well known, leaking due to inappropriate anastomosis at the time of surgical reconstruction, radiation therapy, ileus, infection, and ischemia due to improper blood supply at the site are possible causes. ${ }^{56}$ In most patients, stenosis of the anastomotic site requires symptomatic reoperation or endoscopic treatment; in patients with stenosis at the lower rectum, direct digital dilatation or surgical treatment is possible rather than endoscopic treatment. However, if the stenosis is located in the proximal part, the consequent morbidity and mortality rates owing to surgery are high. Therefore, endoscopic dilatation is used primarily. ${ }^{8,57}$ The success rate for the treatment of colonic anastomotic strictures via endoscopic balloon dilatation is approximately $70 \%-90 \%$; this balloon dilatation is appropriate for strictures if there are no previous radiation therapy and no postoperative anastomotic leak or if the stenosis is short (1 $\mathrm{cm}$ or shorter) and simple in shape; further, if the balloon is large, the success rate is high. The disadvantage of balloon dilatation is the recurrence of anastomotic strictures, which would require repeated dilatation or surgical treatment. ${ }^{57}$ It is often necessary to repeat balloon dilatation twice or thrice. Although no investigators have compared between surgical and endoscopic expansions, endoscopic balloon dilatation for symptomatic anastomotic strictures has been successful, and no serious complications have been reported, except for some bleeding. ${ }^{58,59}$

\section{Strictures due to IBD}

Strictures in IBD are much more common in Crohn's disease (40\%) than in ulcerative colitis (5\%-10\%), ${ }^{10,60,61}$ and they can occur extensively not only in the large intestine but also in the small intestine and duodenum. If the stricture is found in a patient with ulcerative colitis with a long duration of the disease, colon cancer or dysplasia is likely, and thorough biopsy is needed; the role of endoscopy in strictures due to ulcerative colitis can be confirmed by histologic examination and endoscopic treatment. Surgical treatment is recommended for strictures in ulcerative colitis in general; however, endoscopic balloon dilatation can be used in some patients with benign strictures. The indication for endoscopic dilatation in ulcerative colitis is stricture of the ileal pouch, for which it is particularly effective with short (under $1 \mathrm{~cm}$ ) strictures ${ }^{15,62,63}$; for instance, Shen et al.$^{63}$ reported successful palliation of symptoms during 6.1 months of follow-up through an average of 1.74 balloon dilatations in 19 patients with ileal pouch stricture. In contrast, endoscopic balloon dilatation for benign strictures in ulcerative colitis, except for ileal pouch strictures, is very rare. Solt et al. ${ }^{64}$ reported the long-term outcomes of balloon dilatation for lower gastrointestinal stenosis. A total of 57 patients underwent a total of 133 enlargement procedures, including 44 patients with postoperative stricture, 6 with Crohn's disease, and 2 with ulcerative colitis; seven patients had stenoses of other etiologies.

Most of the strictures associated with Crohn's disease are known to be benign; however, malignant strictures are also reported in patients with older and long-term Crohn's disease. In Crohn's disease, the most general site of strictures is known to be the anastomotic site, followed by the distal ileum, ileocecal valve, rectum, and sigmoid colon. ${ }^{65}$ Surgical treatment, such as intestinal resection or strictureplasty, was the mainstay treatment for Crohn's disease with stricture until the mid-1980s. However, owing to the common recurrence of strictures (17\%-81\%), endoscopic nonsurgical treatment plays a major role. Balloon dilatation in Crohn's disease was attempted in 1986 , with an initial success rate of up to $86 \%$ and a long-term clinical efficacy rate of $58 \%{ }^{66}$; it also has limited application in treating long-segment strictures in IBD. In one systematic review, strictures shorter than $4 \mathrm{~cm}$ were associated with a surgery-free outcome. ${ }^{66}$ Balloon dilatation complications include bowel perforation, bleeding, abdominal pain, and infection, and surgical treatment may be necessary if the complication is severe. In one of the largest studies ever reported between 1987 and 2009, Gustavsson et al. ${ }^{67}$ performed 776 endoscopic dilatations in 178 patients; in their study, the technical success rate was $89 \%$, and the rates of patients who needed surgery at 1 , 3 , and 5 years were $13 \%, 28 \%$, and $36 \%$, respectively. Complications occurred in $5.3 \%$ of patients: intestinal perforation in $1.4 \%$, massive bleeding requiring transfusion in approximately $1 \%$, and abdominal pain or infection in $1.5 \%{ }^{67}$

Simultaneous steroid injection has been used in conjunction with balloon dilatation for patients with recurrent strictures to increase the duration of the effect and reduce the need for repeated dilatation or surgery. Investigators of some retrospective case series and a representative study reported favorable outcomes from endoscopic balloon dilatation followed by steroid injection for recurrent strictures ${ }^{68-71}$; steroid injection combined with balloon dilatation has uncertain benefits for the initial treatment of benign colonic strictures. ${ }^{72,73}$ Generally, balloon dilatation for benign colonic strictures is considered safe and effective, but usually requires repeated sessions.

\section{Technique for balloon dilatation}

The goal of conventional balloon dilatation is based on the passage of the endoscope. In cases of active inflammation as a contraindication to balloon dilatation in Crohn's disease, an abscess or a fistula should be considered carefully; it may also be a contraindication if the stricture lesion has acute-angle lesions that the balloon does not spread. Balloon dilatation can expand to a maximum of $8 \mathrm{~cm}$ in strictures; however, most authors only target strictures less than $4 \mathrm{~cm}$ in length. As 
mentioned earlier, one meta-analysis reported that stenoses longer than $4 \mathrm{~cm}$ occurred four times more often than those shorter than $4 \mathrm{~cm}$ in the chance of surgery over a long-term follow-up. ${ }^{66}$ The diameter of the balloon is recommended to be less than $18 \mathrm{~mm}$ to reduce the risk of perforation, although increasing the diameter of the balloon step by step is safe and effective. To avoid perforation during the procedure, the guidewire is first passed through the lesion under the direct observation of the endoscope, and the anatomical structure of the stricture site is then determined using a cannula and contrast agent; the balloon is then positioned through the guidewire and expanded. The balloon is pressurized with saline, contrast, or a mixture thereof, with the contrast required only if fluoroscopy is to be used. Depending on the operator's discretion, the balloon is dilated with a pressure of $35-50$ psi for 1-4 minutes, and the procedure is repeated one to six times generally. The time required to inflate the balloon is not standardized; individual preferences vary. Inflation times of 30, 60 , and 120 seconds are commonly used, and no data suggest superiority over a particular period. ${ }^{74}$

Recently, there have been reports that balloon dilatation followed by local steroid injection improves the effect of dilatation. Strong anti-inflammatory steroids can be injected directly to the stricture site to reduce wound healing and post-dilatation fibrosis, which can reduce the recurrence of strictures more than balloon dilatation alone. Prospective randomized controlled trials should be performed to confirm these results partly because there is no standard for the method and dose. However, in previous reports, $10-160 \mathrm{mg}$ of triamcinolone was injected to the stricture site after balloon dilatation. ${ }^{69,70}$

\section{Other endoscopic therapies for benign colonic ob- struction}

\section{Electroincision}

Electroincision has also been successfully performed together with balloon dilatation to treat anastomotic strictures in uncontrolled studies. ${ }^{75-77}$ Although electroincision for stricture dilatation may be performed alone, additional effects may be obtained with balloon dilatation. ${ }^{78}$ Brandimarte et al. ${ }^{75}$ reported successful management of benign colonic strictures with electroincision using a precut papillotome; in another study, 10 patients were treated effectively with a neodymium:yttrium-aluminum-garnet laser and balloon dilatation. ${ }^{79}$

\section{Endoscopic radial incision and cutting}

Recently, a technique called endoscopic radial incision and cutting (RIC) was developed to treat refractory stenosis of benign esophageal strictures; it has been found to be useful for these refractory strictures. ${ }^{80,81}$ In 2017, a small case series reported treatment of benign colonic anastomotic stenosis using endoscopic RIC for the first time ${ }^{82}$; however, there are still limited data available on its usefulness and safety at sites other than the esophagus. Three patients who developed severe benign anastomotic stenosis after surgical resection for colorectal carcinoma were subsequently treated with RIC dilatation, and the procedure was successful in all of them; two patients experienced improvement after a single RIC session and the other patient after six sessions. The RIC procedure has been performed as previously described ${ }^{80,81}$ using the IT Knife Nano Electrosurgical Knife (Olympus Medical Systems, Tokyo, Japan) (Fig. 5). ${ }^{82}$ The authors suggest that dilatation via

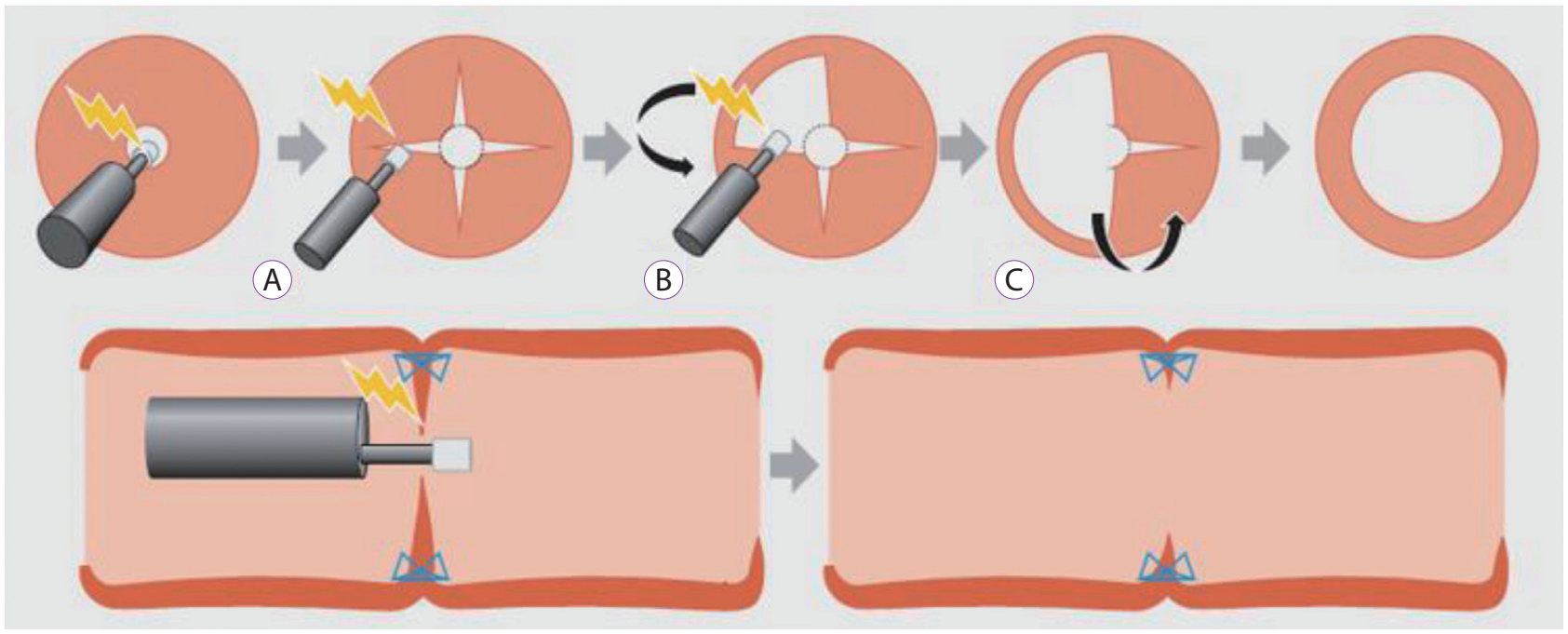

Fig. 5. Schema showing the radial incision and cutting method. ${ }^{81}$ (A) Four or more incisions are created into the stenosed site using the IT Knife Nano (Olympus Medical Systems, Tokyo, Japan). (B) The flaps formed by the incisions are removed using a blade. (C) The scar tissue is excised in an arc from the incision along the lumen. The staples serve as good landmarks for determining the depth of the cutting line. 
RIC is feasible, effective, and safe for severe anastomotic stenosis after surgery for colorectal carcinoma.

\section{Use of sphincterotomes}

In one case series reported in 2014, colorectal anastomotic strictures were relieved using sphincterotomes, which are indicated for cannulating the biliary ducts and for transendoscopic sphincterotomy of the papilla of Vater and sphincter of Oddi $^{83}$; two patients were successfully treated for anastomotic strictures using sphincterotomes (Clevercut; Olympus Medical Systems). In that report, the authors suggested that the use of sphincterotomes can be an effective and a safe treatment option for colonic anastomotic strictures. However, additional research is necessary to evaluate the long-term effects and risks of this method.

\section{Transanal drainage tube placement}

Colonic decompression using transanal drainage tubes (TDTs) can be a valid option for treating acute benign colonic obstruction. In a case series published in 2008, 51 patients with either malignant or benign colonic obstruction were treated with decompression tubes; a technical success rate of $100 \%$ was achieved. ${ }^{84}$ In another report published in 2010 by Ichise et al., ${ }^{85} 69$ patients with acute left-sided colorectal obstruction were treated with TDT placement; the success rate was $96 \%$ (66/69). The use of a combination of TDT and the equipped guidewire enabled successful endoscopic decompression in 45 patients (65\%), and during the procedure, two patients underwent perforation. The authors suggested that TDT placement is safer and more cost-effective than stent insertion.

\section{COLONIC PSEUDO-OBSTRUCTION}

Acute colonic pseudo-obstruction (ACPO) is a disease entity with bowel obstruction due to extensive swelling of the large intestine without mechanical occlusion; it is also called acute colonic ileus and Ogilvie syndrome. ${ }^{86-88} \mathrm{ACPO}$ occurs after surgery or with a severe medical condition. If the enlarged colon is not successfully decompressed via pharmacologic or endoscopic methods, it is a medical emergency that can lead to fatal complications, such as intestinal ischemia and perforation; spontaneous perforation has been reported in 3\%-15\% of patients, and mortality rates of $\geq 50 \%$ have also been reported. ${ }^{89}$ The risk of intestinal ischemia and perforation increases rapidly when the diameter of the cecum exceeds $10-12 \mathrm{~cm}$ for more than 6 days $^{90}$; when assessing patients with signs or symptoms of suspected acute colonic dilatation, mechanical obstruction should be evaluated first because that requires surgical treatment. ACPO usually occurs in association with underlying medical or surgical conditions, most of which are present with more than one factor. Most commonly, ACPO is associated with surgery. ${ }^{91,92}$

\section{Endoscopic therapy for ACPO}

Mechanical decompression of ACPO has included radiologic placement of decompression tubes under fluoroscopic guidance, colonoscopic decompression with or without placement of a decompression tube, and cecostomy via percutaneous, endoscopic, laparoscopic, and open surgical methods. ${ }^{8}$ Among these various invasive therapeutic options, the efficacy of colonoscopic decompression has not been demonstrated in randomized controlled trials; however, it might be performed when there is a high risk of perforation without response to conservative treatment or medication. ${ }^{93,94}$ Although the definite indications for ACPO are not known, endoscopic treatment is attempted if there is no response to conservative or pharmacologic management; the contraindications of colonoscopic decompression are overt perforation and peritonitis. ${ }^{95}$ Colonic endoscopic decompression is performed under unconscious sedation using benzodiazepine alone and without bowel preparation; anticholinergics and opioid analgesics inhibit colonic motility and should not be used. Inadequate cecal intubation increases the risk of perforation, and cecal intubation is unnecessary because of effective decompression by simply depressurizing the stool and gas in the proximal hepatic flexure. ${ }^{96}$ The success rate of colonoscopic decompression was reported to range from $61 \%$ to $95 \%$; however, the recurrence rate was also reported to be as high as $40 \%{ }^{89}$ One third of patients require repeated colonoscopic decompression owing to recurrent colonic distension ${ }^{93}$; to reduce this recurrent pseudo-obstruction, some have reported attempting decompression tube placements. Although there is no comparative study available, retrospective studies have reported that inserting decompression tubes reduces the recurrence rate. ${ }^{94,97}$ The incidence of complications associated with colonoscopic decompression is relatively high: Perforation is reported to occur in $2 \%$ of patients, ${ }^{94,97}$ and mortality is reported to be $1 \%{ }^{98}$ Percutaneous endoscopic colostomy (PEC) may also be an option for treating recurrent or refractory ACPO. ${ }^{8}$ In some small case series, PEC of the cecum was performed through insertion of a percutaneous endoscopic gastrostomy tube combined with endoscopic and radiological methods. ${ }^{99-103}$ The use of PEC should be considered in patients who are at a high risk of undergoing surgery. ${ }^{8}$

\section{CONCLUSIONS}

Although data are limited, various endoscopic techniques 
are available for benign colonic obstruction or pseudo-obstruction, and these procedures have advantages over surgery in selected patients and conditions. However, data are lacking regarding the exact indications; nevertheless, novel techniques and their outcomes are also emerging. Further studies are needed to clarify the role of endoscopic treatment of colonic obstruction in the future.

\section{Conflicts of Interest}

The authors have no financial conflicts of interest.

\section{REFERENCES}

1. Ascanelli S, Navarra G, Tonini G, et al. Early and late outcome after surgery for colorectal cancer: elective versus emergency surgery. Tumori 2003;89:36-41.

2. Bonin EA, Baron TH. Update on the indications and use of colonic stents. Curr Gastroenterol Rep 2010;12:374-382.

3. Billingsley KG, Morris AM, Dominitz JA, et al. Surgeon and hospital characteristics as predictors of major adverse outcomes following colon cancer surgery: understanding the volume-outcome relationship. Arch Surg 2007;142:23-31; discussion 32.

4. Deans GT, Krukowski ZH, Irwin ST. Malignant obstruction of the left colon. Br J Surg 1994;81:1270-1276.

5. Serpell JW, McDermott FT, Katrivessis H, Hughes ES. Obstructing carcinomas of the colon. Br J Surg 1989;76:965-969.

6. Ohman U. Prognosis in patients with obstructing colorectal carcinoma. Am J Surg 1982;143:742-747.

7. Horton KM, Abrams RA, Fishman EK. Spiral CT of colon cancer: imaging features and role in management. Radiographics 2000;20:419430.

8. ASGE Standards of Practice Committee, Harrison ME, Anderson MA, et al. The role of endoscopy in the management of patients with known and suspected colonic obstruction and pseudo-obstruction. Gastrointest Endosc 2010;71:669-679.

9. Gore RM, Levine MS. Textbook of gastrointestinal radiology. 3rd ed. Philadelphia (PA): Saunders; 2008.

10. Gumaste V, Sachar DB, Greenstein AJ. Benign and malignant colorectal strictures in ulcerative colitis. Gut 1992;33:938-941.

11. Ballantyne GH. Review of sigmoid volvulus: history and results of treatment. Dis Colon Rectum 1982;25:494-501.

12. Park IJ, Yu CS, Cho YK, Hong HK, Kim HC, Kim JC. Sigmoid volvulus: is surgical treatment mandatory? J Korean Soc Coloproctol 2001;17:232-238.

13. Lal SK, Morgenstern R, Vinjirayer EP, Matin A. Sigmoid volvulus an update. Gastrointest Endosc Clin N Am 2006;16:175-187.

14. Oren D, Atamanalp SS, Aydinli B, et al. An algorithm for the management of sigmoid colon volvulus and the safety of primary resection: experience with 827 cases. Dis Colon Rectum 2007;50:489-497.

15. Gingold D, Murrell Z. Management of colonic volvulus. Clin Colon Rectal Surg 2012;25:236-244.

16. Madiba TE, Thomson SR. The management of cecal volvulus. Dis Colon Rectum 2002;45:264-267.

17. Kim EJ, Kim YJ. Stents for colorectal obstruction: past, present, and future. World J Gastroenterol 2016;22:842-852

18. Jovani M, Genco C, Bravatà I, Repici A. Stents in the management of benign colorectal strictures. Tech Gastrointest Endosc 2014;16:135-141.

19. Lee JM, Byeon JS. Colorectal stents: current status. Clin Endosc 2015;48:194-200.

20. Chun YJ, Yoon NR, Park JM, et al. Prospective assessment of risk of bacteremia following colorectal stent placement. Dig Dis Sci 2012;57:1045-1049.

21. Baron TH. Colonic stenting: technique, technology, and outcomes for malignant and benign disease. Gastrointest Endosc Clin N Am 2005; 15:757-771.

22. Currie A, Christmas C, Aldean H, Mobasheri M, Bloom IT. Systematic review of self-expanding stents in the management of benign colorectal obstruction. Colorectal Dis 2014;16:239-245.

23. van Hooft JE, van Halsema EE, Vanbiervliet G, et al. Self-expandable metal stents for obstructing colonic and extracolonic cancer: European Society of Gastrointestinal Endoscopy (ESGE) clinical guideline. Gastrointest Endosc 2014;80:747-761.e1-e75.

24. Yang Z, Wu Q, Wang F, Ye X, Qi X, Fan D. A systematic review and meta-analysis of randomized trials and prospective studies comparing covered and bare self-expandable metal stents for the treatment of malignant obstruction in the digestive tract. Int J Med Sci 2013;10:825-835.

25. Zhang Y, Shi J, Shi B, Song CY, Xie WF, Chen YX. Comparison of efficacy between uncovered and covered self-expanding metallic stents in malignant large bowel obstruction: a systematic review and meta-analysis. Colorectal Dis 2012;14:e367-e374.

26. Small AJ, Young-Fadok TM, Baron TH. Expandable metal stent placement for benign colorectal obstruction: outcomes for 23 cases. Surg Endosc 2008;22:454-462.

27. Keränen I, Lepistö A, Udd M, Halttunen J, Kylänpää L. Outcome of patients after endoluminal stent placement for benign colorectal obstruction. Scand J Gastroenterol 2010;45:725-731.

28. Athreya S, Moss J, Urquhart G, Edwards R, Downie A, Poon FW. Colorectal stenting for colonic obstruction: the indications, complications, effectiveness and outcome--5 year review. Eur J Radiol 2006;60:91-94.

29. Keswani RN, Azar RR, Edmundowicz SA, et al. Stenting for malignant colonic obstruction: a comparison of efficacy and complications in colonic versus extracolonic malignancy. Gastrointest Endosc 2009;69(3 Pt 2):675-680.

30. Khot UP, Lang AW, Murali K, Parker MC. Systematic review of the efficacy and safety of colorectal stents. Br J Surg 2002;89:1096-1102.

31. García-Can J. Dilation of benign strictures in the esophagus and colon with the polyflex stent: a case series study. Dig Dis Sci 2008;53:341-346.

32. Dhar A, Close H, Viswanath YK, et al. Biodegradable stent or balloon dilatation for benign oesophageal stricture: pilot randomised controlled trial. World J Gastroenterol 2014;20:18199-18206.

33. Vandenplas Y, Hauser B, Devreker T, Urbain D, Reynaert H. A degradable esophageal stent in the treatment of a corrosive esophageal stenosis in a child. Endoscopy 2009;41 Suppl 2:E73.

34. Griffiths EA, Gregory CJ, Pursnani KG, Ward JB, Stockwell RC. The use of biodegradable (SX-ELLA) oesophageal stents to treat dysphagia due to benign and malignant oesophageal disease. Surg Endosc 2012;26:2367-2375.

35. van Hooft JE, van Berge Henegouwen MI, Rauws EA, Bergman JJ, Busch OR, Fockens P. Endoscopic treatment of benign anastomotic esophagogastric strictures with a biodegradable stent. Gastrointest Endosc 2011;73:1043-1047.

36. Tanaka T, Takahashi M, Nitta N, et al. Newly developed biodegradable stents for benign gastrointestinal tract stenoses: a preliminary clinical trial. Digestion 2006;74:199-205.

37. Toth E, Nielsen J, Nemeth A, et al. Treatment of a benign colorectal anastomotic stricture with a biodegradable stent. Endoscopy 2011;43 Suppl 2 UCTN:E252-E253.

38. Rejchrt S, Kopacova M, Brozik J, Bures J. Biodegradable stents for the treatment of benign stenoses of the small and large intestines. Endoscopy 2011;43:911-917.

39. Karstensen JG, Vilmann P, Hendel J. Successful endoscopic treatment of a 12-cm small-bowel Crohn stricture with a custom-made biodegradable stent. Endoscopy 2014;46 Suppl 1 UCTN:E227-E228.

40. Lorenzo-Zúñiga V, Moreno-de-Vega V, Marín I, Boix J. Biodegradable stents in gastrointestinal endoscopy. World J Gastroenterol 
2014;20:2212-2217.

41. Janík V, Horák L, Hnaníček J, Málek J, Laasch HU. Biodegradable polydioxanone stents: a new option for therapy-resistant anastomotic strictures of the colon. Eur Radiol 2011;21:1956-1961.

42. Rodrigues C, Oliveira A, Santos L, Pires E, Deus J. Biodegradable stent for the treatment of a colonic stricture in Crohn's disease. World J Gastrointest Endosc 2013;5:265-269.

43. Rejchrt S, Kopáčová M, Bártová J, Vacek Z, Bureš J. Intestinal biodegradable stents. Folia Gastroenterologica et Hepatologica 2009;7:7-11.

44. Repici A, Pagano N, Rando G, et al. A retrospective analysis of early and late outcome of biodegradable stent placement in the management of refractory anastomotic colorectal strictures. Surg Endosc 2013;27:2487-2491.

45. Cai XB, Zhang WX, Zhang RL, et al. Safety and efficacy of a novel plastic stent coated with stone-dissolving agents for the treatment of biliary stones in a porcine model. Endoscopy 2015;47:457-461.

46. Shi J, Lv Y, Yu L, et al. Interest of a new biodegradable stent coated with paclitaxel on anastomotic wound healing after biliary reconstruction. Eur J Gastroenterol Hepatol 2013;25:1415-1423.

47. Kim DH, Jeong YI, Chung CW, et al. Preclinical evaluation of sorafenib-eluting stent for suppression of human cholangiocarcinoma cells. Int J Nanomedicine 2013;8:1697-1711.

48. Lee DH, Kang SG, Jeong S, et al. Local delivery system of immune modulating drug for unresectable adenocarcinoma: in vitro experimental study and in vivo animal study. Cardiovasc Intervent Radiol 2006;29:832-837.

49. Jang SI, Kim JH, Kim M, et al. Porcine feasibility and safety study of a new paclitaxel-eluting biliary stent with a Pluronic-containing membrane. Endoscopy 2012;44:825-831.

50. Wang Y, Cai X, Mei J, Liu K, Cai X. Colonic anastomosis with a doxycycline-coated stent: an experimental study in a porcine model. Dig Surg 2014;31:87-94.

51. Li G, Chen Y, Hu J, et al. A 5-fluorouracil-loaded polydioxanone weft-knitted stent for the treatment of colorectal cancer. Biomaterials 2013;34:9451-9461.

52. Graham DY, Smith JL. Balloon dilatation of benign and malignant esophageal strictures. Blind retrograde balloon dilatation. Gastrointest Endosc 1985;31:171-174.

53. ASGE Technology Committee, Siddiqui UD, Banerjee S, et al. Tools for endoscopic stricture dilation. Gastrointest Endosc 2013;78:391-404.

54. Kissin MW, Cox AG, Wilkins RA, Kark AE. The fate of the EEA stapled anastomosis: a clinico-radiological study of 38 patients. Ann R Coll Surg Engl 1985;67:20-22.

55. Luchtefeld MA, Milsom JW, Senagore A, Surrell JA, Mazier WP. Colorectal anastomotic stenosis. Results of a survey of the ASCRS membership. Dis Colon Rectum 1989;32:733-736.

56. Schlegel RD, Dehni N, Parc R, Caplin S, Tiret E. Results of reoperations in colorectal anastomotic strictures. Dis Colon Rectum 2001;44:14641468.

57. Bedogni G, Ricci E, Pedrazzoli C, et al. Endoscopic dilation of anastomotic colonic stenosis by different techniques: an alternative to surgery? Gastrointest Endosc 1987;33:21-24.

58. Ambrosetti P, Francis K, De Peyer R, Frossard JL. Colorectal anastomotic stenosis after elective laparoscopic sigmoidectomy for diverticular disease: a prospective evaluation of 68 patients. Dis Colon Rectum 2008;51:1345-1349.

59. Di Giorgio P, De Luca L, Rivellini G, Sorrentino E, D’Amore E, De Luca B. Endoscopic dilation of benign colorectal anastomotic stricture after low anterior resection: a prospective comparison study of two balloon types. Gastrointest Endosc 2004;60:347-350.

60. De Dombal FT, Watts JM, Watkinson G, Goligher JC. Local complications of ulcerative colitis: stricture, pseudopolyposis, and carcinoma of colon and rectum. Br Med J 1966;1:1442-1447.

61. Van Assche G, Geboes K, Rutgeerts P. Medical therapy for Crohn's disease strictures. Inflamm Bowel Dis 2004;10:55-60.
62. Lou Z, Yu ED, Zhang W, Meng RG, Hao LQ, Fu CG. Appropriate treatment of acute sigmoid volvulus in the emergency setting. World J Gastroenterol 2013;19:4979-4983.

63. Shen B, Fazio VW, Remzi FH, et al. Endoscopic balloon dilation of ileal pouch strictures. Am J Gastroenterol 2004;99:2340-2347.

64. Solt J, Hertelendy A, Szilágyi K. Long-term results of balloon catheter dilation of lower gastrointestinal tract stenoses. Dis Colon Rectum 2004;47:1499-1505.

65. Epidemiological and clinical features of Spanish patients with Crohn's disease. Spanish Epidemiological and Economic Study Group on Crohn's disease. Eur J Gastroenterol Hepatol 1999;11:1121-1127.

66. Hassan C, Zullo A, De Francesco V, et al. Systematic review: endoscopic dilatation in Crohn's disease. Aliment Pharmacol Ther 2007;26:14571464.

67. Gustavsson A, Magnuson A, Blomberg B, Andersson M, Halfvarson J, Tysk C. Endoscopic dilation is an efficacious and safe treatment of intestinal strictures in Crohn's disease. Aliment Pharmacol Ther 2012;36:151-158

68. Lavy A. Triamcinolone improves outcome in Crohn's disease strictures. Dis Colon Rectum 1997;40:184-186.

69. Ramboer C, Verhamme M, Dhondt E, Huys S, Van Eygen K, Vermeire L. Endoscopic treatment of stenosis in recurrent Crohn's disease with balloon dilation combined with local corticosteroid injection. Gastrointest Endosc 1995;42:252-255.

70. Lucha PA Jr, Fticsar JE, Francis MJ. The strictured anastomosis: successful treatment by corticosteroid injections--report of three cases and review of the literature. Dis Colon Rectum 2005;48:862-865.

71. Foster EN, Quiros JA, Prindiville TP. Long-term follow-up of the endoscopic treatment of strictures in pediatric and adult patients with inflammatory bowel disease. J Clin Gastroenterol 2008;42:880-885.

72. East JE, Brooker JC, Rutter MD, Saunders BP. A pilot study of intrastricture steroid versus placebo injection after balloon dilatation of Crohn's strictures. Clin Gastroenterol Hepatol 2007;5:1065-1069.

73. Brooker JC, Beckett CG, Saunders BP, Benson MJ. Long-acting steroid injection after endoscopic dilation of anastomotic Crohn's strictures may improve the outcome: a retrospective case series. Endoscopy 2003;35:333-337.

74. Adler DG. Colonic strictures: dilation and stents. Gastrointest Endosc Clin N Am 2015;25:359-371.

75. Brandimarte G, Tursi A, Gasbarrini G. Endoscopic treatment of benign anastomotic colorectal stenosis with electrocautery. Endoscopy 2000;32:461-463.

76. Truong S, Willis S, Schumpelick V. Endoscopic therapy of benign anastomotic strictures of the colorectum by electroincision and balloon dilatation. Endoscopy 1997;29:845-849.

77. Hagiwara A, Togawa T, Yamasaki J, Shirasu M, Sakakura C, Yamagishi H. Endoscopic incision and balloon dilatation for cicatricial anastomotic strictures. Hepatogastroenterology 1999;46:997-999.

78. Linares L, Moreira LF, Andrews H, Allan RN, Alexander-Williams J, Keighley MR. Natural history and treatment of anorectal strictures complicating Crohn's disease. Br J Surg 1988;75:653-655.

79. Luck A, Chapuis P, Sinclair G, Hood J. Endoscopic laser stricturotomy and balloon dilatation for benign colorectal strictures. ANZ J Surg 2001;71:594-597.

80. Muto M, Ezoe Y, Yano T, et al. Usefulness of endoscopic radial incision and cutting method for refractory esophagogastric anastomotic stricture (with video). Gastrointest Endosc 2012;75:965-972.

81. Yano T, Yoda Y, Satake H, et al. Radial incision and cutting method for refractory stricture after nonsurgical treatment of esophageal cancer. Endoscopy 2013;45:316-319.

82. Asayama N, Nagata S, Shigita K, Aoyama T, Fukumoto A, Mukai S. Effectiveness and safety of endoscopic radial incision and cutting for severe benign anastomotic stenosis after surgery for colorectal carcinoma: a three-case series. Endosc Int Open 2018;6:E335-E339.

83. Chen TA, Hsu WL. Successful treatment of colorectal anastomotic 
stricture by using sphincterotomes. Front Surg 2014;1:22.

84. Fischer A, Schrag HJ, Goos M, Obermaier R, Hopt UT, Baier PK. Transanal endoscopic tube decompression of acute colonic obstruction: experience with 51 cases. Surg Endosc 2008;22:683-688.

85. Ichise Y, Horiuchi A, Nakayama Y, Tanaka N. Techniques and outcomes of endoscopic decompression using transanal drainage tube placement for acute left-sided colorectal obstruction. Gastroenterology Res 2010;3:201-206.

86. Vanek VW, Al-Salti M. Acute pseudo-obstruction of the colon (Ogilvie's syndrome). An analysis of 400 cases. Dis Colon Rectum 1986;29:203210.

87. Dorudi S, Berry AR, Kettlewell MG. Acute colonic pseudo-obstruction. Br J Surg 1992;79:99-103.

88. Vantrappen G. Acute colonic pseudo-obstruction. Lancet 1993;341:152153.

89. Rex DK. Colonoscopy and acute colonic pseudo-obstruction. Gastrointest Endosc Clin N Am 1997;7:499-508.

90. Johnson CD, Rice RP, Kelvin FM, Foster WL, Williford ME. The radiologic evaluation of gross cecal distension: emphasis on cecal ileus. AJR Am J Roentgenol 1985;145:1211-1217.

91. Caner H, Bavbek M, Albayrak A, Altinörs TC. Ogilvie's syndrome as a rare complication of lumbar disc surgery. Can J Neurol Sci 2000;27:7778.

92. O’Malley KJ, Flechner SM, Kapoor A, et al. Acute colonic pseudo-obstruction (Ogilvie's syndrome) after renal transplantation. Am J Surg 1999;177:492-496.

93. Jetmore AB, Timmcke AE, Gathright JB Jr, Hicks TC, Ray JE, Baker JW. Ogilvie’s syndrome: colonoscopic decompression and analysis of predisposing factors. Dis Colon Rectum 1992;35:1135-1142.

94. Geller A, Petersen BT, Gostout CJ. Endoscopic decompression for acute colonic pseudo-obstruction. Gastrointest Endosc 1996;44:144-150.

95. Fiorito JJ, Schoen RE, Brandt LJ. Pseudo-obstruction associated with colonic ischemia: successful management with colonoscopic decompression. Am J Gastroenterol 1991;86:1472-1476.

96. Saunders MD. Acute colonic pseudo-obstruction. Best Pract Res Clin Gastroenterol 2007;21:671-687.

97. Saunders MD, Kimmey MB. Systematic review: acute colonic pseudo-obstruction. Aliment Pharmacol Ther 2005;22:917-925.

98. Kahi CJ, Rex DK. Bowel obstruction and pseudo-obstruction. Gastroenterol Clin North Am 2003;32:1229-1247.

99. Lynch CR, Jones RG, Hilden K, Wills JC, Fang JC. Percutaneous endoscopic cecostomy in adults: a case series. Gastrointest Endosc 2006;64:279-282.

100. Ramage JI Jr, Baron TH. Percutaneous endoscopic cecostomy: a case series. Gastrointest Endosc 2003;57:752-755.

101. Chevallier P, Marcy PY, Francois E, et al. Controlled transperitoneal percutaneous cecostomy as a therapeutic alternative to the endoscopic decompression for Ogilvie's syndrome. Am J Gastroenterol 2002;97:471-474.

102. vanSonnenberg E, Varney RR, Casola G, et al. Percutaneous cecostomy for Ogilvie syndrome: laboratory observations and clinical experience. Radiology 1990;175:679-682.

103. Ganc AJ, Netto AJ, Morrell AC, Plapler H, Ardengh JC. Transcolonoscopic extraperitoneal cecostomy. A new therapeutic and technical proposal. Endoscopy 1988;20:309-312. 